\title{
Can Implicit Measures Contribute to a True Understanding of People's Attitudes and Stereotypes?
}

\author{
Brian O'Shea, Institute of Advanced Study and Department of \\ Psychology, University of Warwick \\ Address \\ Correspondence: b.oshea@warwick.ac.uk
}

\begin{abstract}
Traditionally psychologists used explicit self-reports to better understand individuals' attitudes but influences such as social desirability and impression management often made this method of data collection unreliable. This article describes the origins and the advancements of one of the most studied topics in social psychology - Implicit Social Cognition. Unobtrusive/indirect research methods were initially used to overcome the problems of using self-reports. Subsequently, reaction time tasks such as the Implicit Association Test (IAT) were developed to enable researchers to measure response biases, at the individual level, in socially sensitive domains such as prejudice towards minority groups.

Automaticity is a core requirement for a measure to be described as implicit and therefore, fast reaction times ( $<2,000$ milliseconds) are needed. This article will describe under what conditions implicit and explicit measures are and are not related, including the theoretical basis for these relations. The value of using both implicit and explicit measures to predict behaviour will be explained, along with a discussion on what implicit measure are detecting. In certain domains or under specific conditions, implicit measures can contribute to providing a true understanding of attitudes and stereotypes.
\end{abstract}

Peer review: This article has been subject to a double-blind peer review process

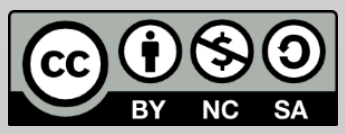

C Copyright: The Authors. This article is issued under the terms of the Creative Commons Attribution NonCommercial Share Alike License, which permits use and redistribution of the work provided that the original author and source are credited, the work is not used for commercial purposes and that any derivative works are made available under the same license terms.
Keywords:

Social Psychology, Implicit Social Cognition, Implicit Association Test, Attitudes, Stereotypes, Predicting Behaviour.

\section{Origins of research into implicit social cognition}

Most psychologists agree that to gain a comprehensive understanding of an individual's behaviour one needs knowledge not only of the external contexts in which an individual is situated but also of their internal psychological attributes (i.e., attitudes, stereotypes and personality traits). The cognitive revolution of the 1960s and 70s challenged behaviourism's grip on psychology and restored the scientific respectability of the study 
of internal psychological processes (Miller, 2003). Without this impetus, the study of implicit cognition and investigations into the importance of unconscious/unexpressed biases influencing behaviour could have been further delayed. The term implicit is often used as a synonym for other labels such as unconscious, unaware, intuitive, indirect and automatic. Likewise, explicit often overlaps with the terms conscious, aware, analytic, direct and controlled. The implicit-explicit distinction will be used throughout this article.

The prominence in social psychology of the study of individuals' attitudes was apparent as far back as the 1930s, when George Allport (1935: 198), described attitudes as the 'most distinctive and indispensable concept' in the discipline. In the 1940s the behaviourist Leonard Doob (1947: 136) defined an attitude as 'an implicit, drive-producing response considered socially significant in the individual's society'. It was generally accepted, albeit implicitly, that attitudes were influenced by unconscious mechanisms (Greenwald \& Banaji, 1995). This (implicit) acceptance was likely due to psychoanalytic theory according to which attitudes could be influenced by unconscious processes. Although psychologists often want to dissociate themselves from Sigmund Freud's controversial and often unfalsifiable ideas, he was one of the first individuals to bring the idea of the unconscious to the mainstream (Freud, 1915, 2005).

Researchers aimed to measure attitudes using more objective methods such as questionnaires. Nevertheless, the near-universal use of self-report questionnaires throughout social psychology's past has led to numerous problems. One of the major problems was construct validity weaknesses, as seen by the lack of correspondence between attitudes and behaviour (Greenwald, 1990, see also Nisbett \& Wilson, 1977). For example, LaPiere (1934) reported that when he visited 251 accommodation venues with a Chinese couple, only one venue refused them admission. Following these visits, letters were sent to all 251 venues asking for a response to the question 'Will you accept members of the Chinese race as guests in your establishment?' and over $90 \%$ responded that they would not. Regardless of the limitations of the study, (e.g., the Chinese couple was accompanied by an individual in a high-status profession; the person rejecting the letter request may have been different from the person who accepted their face to face request), LaPiere's study emphasises the values of using unobtrusive/indirect research methods instead of confining oneself to explicit self-reports (direct measures). To clarify, the terms indirect and direct are often used to describe the procedural characteristics of a measurement procedure, while the terms implicit and explicit are often used to describe the psychological features or attributes assessed by measurement procedures (De Houwer, Teige-Mocigemba, Spruyt, \& Moors, 2009; see also De Houwer \& Moors, 2010). ${ }^{\text {. }}$ 


\section{Unobtrusive and indirect research methods}

Unobtrusive refers to methods in which participants are generally unaware that their behavioural responses are under investigation, while the term indirect refers to when participants are aware their responses are being monitored but it is unclear exactly which aspect of their behaviour is being assessed (Banaji \& Greenwald, 2016). In the 1970's, two social forces made unobtrusive research methods both more appealing and more popular: (1) The rise in the scientific study of prejudice across the US due to racial tensions, and (2) the growing realisations that participants often respond in a socially desirable manner when making explicit selfreports (Banaji \& Greenwald, 2016; Jones \& Sigall, 1971). The first two successful uses of unobtrusive methods relating to racial prejudice showed that (1) when black and white research assistants (RAs) separately called looking for help through the telephone, the white RAs were more likely to receive assistance (Gaertner \& Bickman, 1971). The black and white RAs were distinguished from each other by varying their speech characteristics such as the pronunciation of words. (2) When an open unsent student application with a portrait photograph attached was left at an airport telephone booth, participants were more likely to voluntarily submit applications for the white rather than the black students (Benson et al., 1976). ${ }^{i i}$

Crosby and colleagues (1980) indicated that discrimination is more prevalent than explicit self-reports would lead us to believe, and that remote (not face to face) interactions were more likely to give rise to stronger racial prejudice when unobtrusive methods were used. Unobtrusive methods reduce the Hawthorne effect. This effect occurs when participants' knowledge of being in an experiment modifies their behaviour from how they would have responded without that knowledge (Adair, 1984). Importantly, unobtrusive methods can be ethically problematic, require more resources to run than simple questionnaires, and the context is more difficult to control (Blackstone, 2017). Of most relevance, they do not provide an adequate opportunity to measure individual differences because asking participants to fill out questionnaires or demographic information would rouse suspicions. Indirect measures, such as implicit measures, were developed to overcome the limitation of unobtrusive methods not assessing individual differences.

\section{Selective attention and implicit memory}

Research relating to both selective attention and implicit memory greatly influenced the development of research into implicit social cognition (Payne \& Gawronski, 2010). With respect to selective attention, a key distinction was one between controlled and automatic/involuntary modes 
of information processing (e.g., Shiffrin \& Schneider, 1977). For example, our attention will be instantly drawn if we detect words of importance originating from unattended sources, such as hearing one's name. Research on implicit memory pioneered by Jacoby and colleagues (e.g. Jacoby, Toth, Lindsay, \& Debner, 1992) iii strongly influenced Greenwald and Banaji's (1995) seminal paper on implicit cognition (see also Banaji, 2001). Essentially, studies of implicit memory showed that participants found it easier to perceive stimuli that they had previously seen (perceptual fluency) but attributed this ease to characteristics of the stimulus, rather than to the recent past encounter. These ideas led Greenwald and Banaji (1995: 5) to coin the term implicit cognition and define it as 'An implicit $\boldsymbol{C}$ is the introspectively unidentified (or inaccurately identified) trace of past-experience that mediates $\boldsymbol{R}$. In this template, $\boldsymbol{C}$ is the label for a construct (such as attitudes), and $\boldsymbol{R}$ names the category of responses (such as object evaluative judgements) assumed to be influenced by that construct' Their review focused on how implicit cognition was specifically related to attitudes, stereotypes and the self.

In implicit memory research, experimenters normally have perfect control over the stimuli previously presented, while in implicit cognition, experimenters generally have little control over previously presented stimuli (e.g., an individual's life history) and therefore, require more mentalistic explanations for behavioural responses such as mental associations, particularly evaluative and semantic associations (Greenwald et al., 2002; Hahn \& Gawronski, 2015). An exception is when participants are exposed to completely new stimuli. Any attitude (both implicit and explicit) that subsequently develops following a positive or negative induction to novel stimuli (e.g., an unknown group or tribe), is most likely due to the controlled exposure rather than prior experiences (e.g., Gregg, Seibt, \& Banaji, 2006; Olson \& Fazio, 2001). This experimental set up has been said to involve attitude formation and refers to the initial change from having no attitude towards an object to having some attitude, either positive or negative, towards it (Oskamp \& Schultz, 2005).

\section{The development of implicit measures}

Greenwald and Banaji (1995) asserted that the measurement of individual differences in implicit cognition is likely to be possible and described judgement latency (i.e., reaction time (RT)) measures as a potentially fruitful avenue to pursue this goal. They predicted that 'when such measures become available, there should follow the rapid development of a new industry of research on implicit cognitive aspects of personality and social behaviour' (ibid, p. 20). Within three years, the same authors developed and published the first and still most popular RT task that aims 
to measure implicit attitudes, stereotypes and self-concept at the individual level. The measure was called the Implicit Association Test (IAT) (Greenwald et al., 1998) and precisely as they predicted, this task led to an acceleration in research into implicit cognition, with the area being described as 'one of the liveliest and most active research areas in social psychology' (Payne \& Gawronski, 2010).

The initial IAT publication has to date (March 2018) been cited over 9,700 times. Development of the IAT to run online through Project Implicit (https://implicit.harvard.edu/implicit/), the world's largest online virtual laboratory, greatly accelerated the speed at which the IAT could be validated (Greenwald et al., 2003; Greenwald \& Nosek, 2001; Nosek et al., 2007; Nosek et al., 2002, 2007). Millions of people from all over the world have completed various versions of the IAT through Project Implicit (e.g., Old-Young IAT, Fat-Thin IAT, European American-African American IAT). Participants are incentivised to complete IATs because after completing the task they are given their implicit bias score towards the categories to which they were responding. Additionally, teachers and lecturers often ask their students to complete IATs on Project Implicit for course credits and to teach them about implicit biases.

In a typical IAT, such as the Young-Old IAT, participants are presented successively with various pictures of young and old individuals as well as positively (e.g., cheerful, joy, love) and negatively (e.g., evil, hurt, sick) valenced words. Only one picture or word item is presented at the centre of the computer screen at any point and using the appropriate key press, it must be sorted into the correct category (i.e., Young, Old, Good, Bad) which appear at the top of the screen (see Figure 1). The first three blocks in the IAT are practice blocks to ensure the participants can respond fast and accurately to the stimuli presented. In block 4, one of the two critical blocks, participants should press the E key on a computer keyboard if a negative word or a picture of an old person appears and press the I key if a positive word or a picture of a young person appears (congruent block, see Figure 1 Left). 


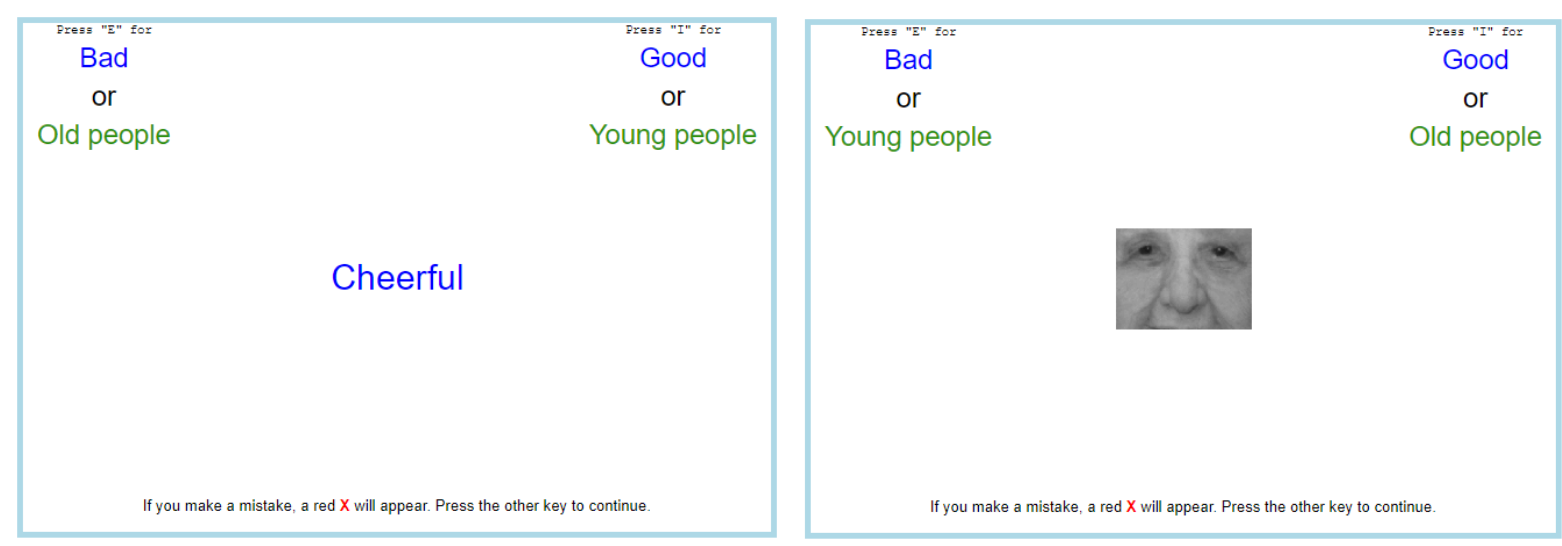

Figure 1: (Left) Screen shot example of the congruent block in the Young-Old Implicit Association Test (IAT). (Right) Screen shot example of the incongruent block in the Young-Old IAT. Copyright Project Implicit

Next participants complete two more practice blocks due to the Old and Young word categories at the top of the screen switching location. In the other and final critical block (block 7), participants should press $E$ if a negative word or a picture of a young person is shown and they must press the I key for a positive word or a picture of an old person (incongruent block, see Figure 1 Right). To reduce order effects, participants randomly complete either the congruent or incongruent critical block first, followed by the other critical block. This task aims to measure biases participants have in associating concepts (old and young) with valenced words. The stronger the association, the more natural the sorting task will feel and hence, result in faster responses (congruent block), while weaker associations will result in a slowing down of processing, due to the need to make use of unaccustomed pairings in memory (incongruent block) ( Greenwald et al., 2002). Generally, both young and old participants have quicker reaction times when Young is paired with Good and Old is paired with Bad (hence the name congruent block) then when Old is paired with Good and Young is paired with Bad (hence the name incongruent block). These results have been interpreted as participants having a pro-young or anti-old implicit bias. Lastly, rather than using positive and negative valenced words to measure attitudes, stereotypical words could be used instead (e.g., healthy, lively, frail, slow, etc.) to measure stereotypes that individuals have.

\section{What is an implicit measure?}

Currently, the term implicit social cognition is generally used to refer to research in social psychology that uses computerised RT measurement instruments to infer an individual's psychological attributes (i.e., attitudes, stereotypes, self-esteem, etc.) without asking an individual to report their psychological attributes directly (Hahn \& Gawronski, 2015). Implicit 
measures have been defined as the outcome of a measurement procedure that results from automatic processes by which the to-bemeasured attribute causally determines the outcome' (De Houwer et al., 2009: 363). Automaticity has been argued to be one of the core features of an implicit measure and occurs when the impact of the to be measured attribute on an individual's responses is uninfluenced by certain goals, substantial cognitive resources, awareness or substantial time (Bargh, 1994; De Houwer, 2006; De Houwer \& Moors, 2012). Therefore, quick and accurate reactions to stimuli are necessary $(<2,000$ milliseconds) to limit an individual's ability to exercise strategic control over their responses. This automaticity aspect or feature distinguishes implicit measures from traditional instruments that rely on explicit self-reports (Gawronski \& De Houwer, 2014). Consequently, the speed or accuracy with which an individual responds to or associates stimuli in implicit measures is used to infer their psychological attributes (De Houwer, 2009; De Houwer, 2003; Nosek \& Banaji, 2001). With implicit measures (and also explicit measures), an inference must inevitably be used because it is not possible to directly observe psychological attributes.

An ideal measure of implicit attitudes would provide an accurate index of the extent to which an individual possesses the psychological attributes that the measure was designed to capture (De Houwer et al., 2009). To validate an implicit measure, there must be evidence that variation in the to be measured attribute (e.g. racial bias), causes variations in the measurement outcome (i.e., the measure's score), but an understanding of how the measurement outcome is detecting variations in the psychological attribute is also necessary (Borsboom et al., 2004; Wentura \& Rothermund, 2007). Both correlations and experimental approaches are useful when validating implicit measures. But collecting correlational data is the most time and cost effective way to validate an implicit measure (De Houwer et al., 2009). The more evidence that is accumulated showing that the implicit measure correlates in the expected manner with other measures of psychological attitudes (e.g., explicit self-reports), the more the likelihood that the correlations are due to a third factor is reduced (Nosek \& Smyth, 2007).

\section{What are implicit measures detecting?}

Early theorising around implicit measures assumed that they provide direct access to stable evaluative representations that have their roots in long-term socialisation experiences (Greenwald \& Banaji, 1995). However, new evidence has shown that implicit attitudes are highly susceptible to contextual influence. ${ }^{\text {iv }}$ Furthermore, the debate surrounding whether implicit biases represent person-based (e.g., personal attitudes (Fazio et al., 1995) or situational-based approaches 
(e.g., awareness of cultural stereotypes (Devine, 1989) has been going on for some time. More recently, this debate has re-emerged in the form of personal versus extra-personal associations in the IAT (Nosek \& Hansen, 2008; Olson et al., 2009). However, it has been argued that making a distinction between situational and personal views is not warranted due to the automatic effects of implicit biases (Banaji, 2001; Gawronski \& LeBel, 2008; Nosek \& Hansen, 2008). It has also been stated that few arguments remain supporting the claim that IAT effects are causally influenced by extra-personal views (De Houwer et al., 2009).

The term implicit has often been used synonymously with unconscious but one must ask the question: Are implicit measures uncovering unconscious representations? The available evidence challenges the notion that implicit measures offer a window into people's unconscious processes (Gawronski et al., 2006; Hahn \& Gawronski, 2014). To clarify, the majority of participants in Monteith, Voils, and Ashburn-Nardo's (2001) study expressed that they found the incongruent block on the Race IAT (BlackPositive) more challenging, and they felt guilty about it to the extent that they attributed the bias to racial prejudice. Therefore, individuals appear to have much greater introspective access to their mental representation than was originally assumed (Payne \& Gawronski, 2010). For example, across five different social groups, participants were surprisingly accurate when predicting their implicit biases (Hahn et al., 2014), emphasising that participants can have introspective awareness of their implicit bias. Of note, the mental processes that result in conscious experience for introspection to occur are largely a mystery, and similarly, our knowledge of what implicit measures are detecting is less mature than our knowledge about what implicit measures do (Nosek et al., 2011).

\section{Refining and expanding the use of implicit measures}

The period following the IAT's first publication has been described as the age of measurement in social psychology, due to the development of various implicit measures each of which aimed to measure psychological attributes accurately (Nosek et al., 2011). New implicit measures were developed mainly because of limitations in the IAT. But these new measures were further challenged by the need to preserve the strong psychometric properties that the IAT achieves. The brief IAT (BIAT) was developed to give researchers a tool that could be used to measure implicit bias in a shorter amount of time. However, like the IAT, the BIAT only measures implicit biases relatively (e.g., attitudes to fat people relative to attitudes to thin people). It is therefore impossible to determine using these IATs whether this bias is the result of a strong/weak pro-thin bias, a strong/weak anti-fat bias, or some combination of the two (Blanton \& Jaccard, 2006; Roddy et al., 2010, 2011). Likewise, the IAT cannot be 
used to determine how interventions that aim to increase or reduce implicit biases have their effect (e.g., a difference in implicit attitudes could be reduced by acting on the Thin Person category, the Fat Person category, or both (Lai et al., 2014).

Another limitation of the IAT arises because some categories do not have an obvious comparison group. For example, when assessing implicit selfesteem, researchers can use the IAT to measure the positive and negative associations a person has with the self in comparison to a specified/unspecified other (or with me in comparison to not me). The type of comparison category (i.e., specified vs. unspecified other) used affects implicit self-esteem results (Karpinski, 2004). Therefore, a more appropriate approach would measure only evaluative associations with the self, without the need to use a complementary category.

To address these problems, RT tools that attempt to measure absolute attitudes and do not require a relative comparison to another group have been developed. For example, the go/no-go (Nosek \& Banaji, 2001) and the extrinsic affective Simon task (De Houwer, 2003b) both claim to measure implicit attitudes non-relatively/absolutely. However, both suffer from problems ranging from a high level of task difficulty to low reliability (Bar-Anan \& Nosek, 2014; De Houwer \& De Bruycker, 2007). Variations of the IAT that could be described as single concept IATs, such as the Single Target/Category IAT (Bluemke \& Friese, 2008; Karpinski \& Steinman, 2006) have, however, shown promise for measuring absolute implicit attitudes. The Implicit Relational Assessment Procedure (IRAP) (BarnesHolmes et al., 2006) is another absolute implicit measures, but recent evidence has indicated that the IRAP cannot accurately measures absolute biases only relative bias like the IAT (O'Shea et al, 2016).

The Single-Block IAT (Sarah Teige-Mocigemba et al., 2008), the Recoding Free IAT (Klaus Rothermund et al., 2009) and the Sorting Paired Features Task (Bar-Anan et al, 2009) were developed to overcome the problem of block structure influencing the accurate measurement of implicit biases. For example, the order in which a participant completes the congruent and incongruent blocks can influence the IAT score (Nosek, et al., 2007; TeigeMocigemba et al., 2010). Efforts have been made to reduce the order effect in the IAT (Nosek et al., 2005) but it is nevertheless difficult to determine the magnitude of order effects at the individual level and hence it is not possible to fully remove effects of this confound (De Houwer et al., 2009). Another reason for removing the block structure in the IAT was that the salience of the items within a block, not the associations between the items, can lead to an IAT effect (Rothermund \& Wentura, 2001, 2004). 
Several authors have identified unwanted factors (Friese \& Fiedler, 2009) or nonassociative influences (Rothermund \& Wentura, 2010) that influence the magnitude of IAT effects. If IAT effects can be caused by processes other than just mental associations in memory, and if it is not clear which processes influence the IAT effect, then the meaning of the effect becomes ambiguous (Fiedler et al., 2006). There is increasing evidence that findings relating to implicit measures can reflect several processes, such as salience of the stimuli (Houben \& Wiers, 2006; Rothermund et al., 2005), similarity between the stimuli (De Houwer, et al., 2005) and cognitive ability of participants (Back et al., 2005; McFarland \& Crouch, 2002). Greenwald's (et al., 2003) D-algorithm has greatly reduced the problem relating to cognitive ability because it accounts for an individual's variation in responding across the IAT. More research is needed to explain the relative impact that salience and similarity can have on IAT scores (De Houwer et al., 2009; Conrey et al., 2005; Klauer et al., 2007). IAT researchers have acknowledged these problems, emphasising that no measure is perfect but yet the measure can still be useful (Greenwald \& Sriram, 2010). ${ }^{\text {vi }}$

\section{Implicit and explicit correlations}

Correlations between implicit and explicit measures of attitudes vary widely, from weakly positive ( $r=.250$; e.g. thin people-fat people) to strongly positive ( $r=.780$; democrats-republicans) with a median correlation of .48 found for 56 domains across 6000 participants (Nosek, 2007). There are a number of possible reasons for this disparity, with the most obvious being self-presentation/socially desirable responding. This is especially true for socially sensitive topics, where demand characteristics (i.e., similar to the Hawthorne effect described above) and/or impression management may distort self-report responses (e.g. Fazio, 2007; Holtgraves, 2004). Implicit and explicit correlations have been shown to be higher for affective responses (emotions and feelings about the attitude object) on explicit measures compared to more cognitive responses (thoughts and beliefs about the attitude object) on explicit measure (Smith \& Nosek, 2011), for a review see Spence and Townsend (2008).

Reducing the time allocated for a participant to think about their response on the explicit measures produces higher correlations between implicit and explicit measures (Ranganath et al., 2008). Another crucial aspect to consider is that implicit and explicit correlations will be stronger for attitudes that are more familiar or beliefs that are important or well elaborated in memory, as opposed to ones that are rarely thought about or believed to be irrelevant (Nosek, 2007). Conceptual correspondence and structural fit between implicit and explicit measures increases the 
correlations between these two measures. Additionally, due to averaging out noise and the inclusion of more trials, relative scores (e.g., IAT scores) rather than absolute scores (e.g., SC-IAT scores) show stronger implicit and explicit correlations (Hofmann et al., 2005; Payne et al., 2008).

Lack of a perfect correlation between implicit and explicit measures has been cited as evidence for the distinct constructs that these measures assess (Greenwald \& Nosek, 2008; Nosek \& Smyth, 2007). Yet the divergence could also be due to a number of other factors (e.g., awareness, need for cognition, structural features) $)^{\text {vii }}$ Importantly, much research demonstrates the practical value of implicit measures for predicting human behaviour (Friese et al., 2009; Perugini et al., 2010), especially spontaneous behaviours ${ }^{\text {viii }}$ and shows that implicit measures can provide information that is distinct from explicit measures (Nosek et al., 2011).

The two most prominent theories aiming to explain correlations between implicit and explicit measures are the motivations and opportunity as determinants (MODE) model (Fazio \& Olson, 2014; Fazio, 1990) and the Associative Propositional Evaluation (APE) model (Gawronski \& Bodenhausen, 2006, 2011). Both these models make similar predictions but differ in a few subtle ways. Motivation (e.g., social desirability) (Devine et al., 2002; Dunton \& Fazio, 1997) and the opportunity (e.g., selfregulation resources) (Hofmann et al., 2007) are the primary determinates explaining implicit and explicit correlations in the MODE model. In the APE model, however, cognitive consistency (i.e., rejecting affective racial biases in favour of more explicit egalitarian values) is an important factor in explaining implicit and explicit correlations (Brochu et al., 2011; Gawronski et al., 2008).

The MODE model assumes that the same underlying representations are measured using direct and indirect methods, while the APE model assumes they are part of a distinct but mutually reinforcing processes (i.e., associative and propositional processes). The MODE model also assumes that deliberate processing reduces implicit and explicit correlations, while in the APE model deliberating on information that is consistent with an activated association (i.e., implicit bias) will increase implicit and explicit correlations (Galdi, Gawronski, Arcuri, \& Friese, 2012; Peters \& Gawronski, 2011). For a full review of the numerous dual process theories of human cognition see Chaiken and Trope (1999) and Strack and Deutsch (2004). 


\section{Using implicit measures to predict behaviour}

Perugini, Richetin, and Zogmaister (2010) described how implicit measures could contribute to predicting behaviour over and above explicit measures. These include: (1) separate patterns with implicit measures, but not explicit measures uniquely predicting behaviour (2) additive patterns in which both implicit and explicit measures contribute to predicting behaviour, (3) double dislocation patterns where both measures uniquely predict different types of behaviour (4) moderation patterns where both measures predict behaviour under different conditions, (5) multiplicative patterns where both measures interactively predict behaviour. All these patterns have been shown in the literature. However, the boundary conditions specifying when each will occur are not thoroughly understood, making it difficult to make a priori predictions (Gawronski \& De Houwer, 2014).

The most thorough evidence emphasising the value of implicit measures was provided by a meta-analysis of studies using the IAT, which showed it to predict stereotyping or racially prejudicial behaviour better (average $r=$ .236) than did explicit self-report measures (average $r=.118$ ) (Greenwald et al., 2009; Cameron et al., 2012). However, see Oswald, Mitchell, Blanton, Jaccard, and Tetlock (2013: 188), for a more critical view of the predictive validity of the IAT. They showed that that IAT only weakly predicted racial attitudes and stereotypes $(r=.148)$ and stated that 'the IAT provides little insight into who will discriminate against whom'. For a recent defence of the IAT's predictive abilities see Greenwald, Banaji, and Nosek (2015).

If participants are tired, distracted or rushed, they are more likely to respond based on implicit biases than when they have energy, are concentrating, focused or unhurried (Strack \& Deutsch, 2004). For example, Friese, Hofmann, and Wänke (2008) found that when participants' self-regulation resources were reduced, they were more likely to respond behaviourally (eating or drinking) in accordance with their implicit attitudes. In contrast, when participants maintained these control resources, their behavioural responses were better predicted by their explicit attitudes. Furthermore, implicit measures have been shown to be better at predicting behaviours of individuals with a preference for intuitive thinking styles, while explicit measures are better for those with a preference for rational thinking styles (Richetin et al., 2007).

Other examples of the usefulness of implicit measures for predicting behaviour include: (1) countries with stronger implicit biases of associating males rather than females with science and maths, predict larger performance gaps between males and females in these disciplines (Nosek et al., 2009), (2) those with low self-esteem on implicit measures exhibit 
various defensive behaviours (Jordan et al., 2003) (3) more strongly associating the self with death prospectively predicted suicide ideation as well as suicide attempts (Nock et al., 2010; Nock \& Banaji, 2007) and (4) higher implicit racial biases predicted increased job interview invitations to racial in-group members (Rooth, 2010). Importantly, neither implicit and explicit measures can be described as a truer measure of one's beliefs, because both predict unique aspects of behaviour (Banaji, Nosek, \& Greenwald, 2004). To clarify, explicit measures are generally better at predicting political preferences (Friese et al., 2016) and consumer behaviour (Friese et al., 2006), while implicit measures are particularly suited when addressing more social sensitive topics such as intergroup attitudes/interactions (Greenwald et al., 2009).

\section{Conclusion}

This article has highlighted some of the most relevant information related to implicit cognition (i.e., correlations between implicit and explicit measures and the ability of implicit measures to predict behaviour). RT computer-based tasks such as the IAT have been crucial to the area's success. Based on the accumulation of evidence described above, it is recommended that implicit measures should be used to complement other methods (e.g., explicit self-reports) used to address attitudes and stereotypes. Almost every intellectual question in social psychology, and some outside it, has been shaped in some way by the methods and theories related to implicit social cognition (Payne \& Gawronski, 2010). New implicit measures, such as the Relational Responding Task De Houwer, Heider, Spruyt, Roets, \& Hughes, 2015) and the SIP (O'Shea et al., 2016) have the strong potential of building on the success of the IAT and continuing the research momentum the IAT has generated in implicit cognition throughout the past twenty years.

\section{References}

Adair, J. G. (1984). The Hawthorne effect: A reconsideration of the methodological artifact. Journal of Applied Psychology, 69(2), 334-345. https://doi.org/10.1037/0021-9010.69.2.334

Allport, G. W. (1935). Attitudes. In C. Murchison, A handbook of social psychology (pp. 798-844). Worcester, MA: Clark University Press.

Retrieved from

http://noneedtoread.blogsport.de/images/allportattitudes.pdf

Back, M. D., Schmukle, S. C., \& Egloff, B. (2005). Measuring task-switching ability in the Implicit Association Test. Experimental Psychology, 52(3), 167-179. https://doi.org/10.1027/1618-3169.52.3.167 
Banaji, M. R. (2001). Implicit attitudes can be measured. In H. L. Roediger \& I. N. Nairne, The nature of remembering: Essays in honor of Robert G. Crowder. (pp. 117-149). Washington, D.C.: APA. Retrieved from http://www.people.fas.harvard.edu/ banaji/research/publications/articl es/2001_Banaji_HLRoediger.pdf

Banaji, M. R., \& Greenwald, A. G. (2016). Blindspot: Hidden Biases of Good People. New York, NY: Bantam.

Banaji, M. R., Nosek, B. A., \& Greenwald, A. G. (2004). No place for nostalgia in science: A response to Arkes and Tetlock. Psychological Inquiry, 15(4), 279-289.

Bar-Anan, Y., \& Nosek, B. A. (2014). A comparative investigation of seven indirect attitude measures. Behavior Research Methods, 46(3), 668-688. https://doi.org/10.3758/s13428-013-0410-6

Bar-Anan, Y., Nosek, B. A., \& Vianello, M. (2009). The Sorting Paired Features Task: A Measure of Association Strengths. Experimental Psychology, 56(5), 329-343. https://doi.org/10.1027/1618-3169.56.5.329

Bargh, J. A. (1994). The Four Horsemen of Automaticity: Awareness, Intention, Efficiency, and Control in Social Cognition. In R. Wyer \& T. Srull (Eds.), Handbook of Social Cognition. Mahwah, NJ, US: Lawrence Erlbaum.

Barnes-Holmes, D., Barnes-Holmes, Y., Power, P., Hayden, E., Milne, R., \& Stewart, I. (2006). Do you really know what you believe? Developing the Implicit Relational Assessment Procedure (IRAP) as a direct measure of implicit beliefs. The Irish Psychologist, 32(7), 169-177.

Benson, P. L., Karabenick, S. A., \& Lerner, R. M. (1976). Pretty pleases: The effects of physical attractiveness, race, and sex on receiving help. Journal of Experimental Social Psychology, 12(5), 409-415. https://doi.org/10.1016/0022-1031(76)90073-1

Blackstone, A. (2017). Principles of Sociological Inquiry: Qualitative and Quantitative Methods. Retrieved from http://catalog. flatworldknowledge.com/bookhub/reader/3585?e=blackst one_1.0-ch11_s02

Blair, I. V. (2002). The Malleability of Automatic Stereotypes and Prejudice. Personality and Social Psychology Review, 6(3), 242-261. https://doi.org/10.1207/S15327957PSPR0603_8

Blanton, H., \& Jaccard, J. (2006). Arbitrary metrics in psychology. American Psychologist, 61(1), 27-41. https://doi.org/10.1037/0003066X.61.1.27 
Bluemke, M., \& Friese, M. (2008). Reliability and validity of the SingleTarget IAT (ST-IAT): Assessing automatic affect towards multiple attitude objects. European Journal of Social Psychology, 38(6), 977-997.

https://doi.org/10.1002/ejsp.487

Borsboom, D., Mellenbergh, G. J., \& van Heerden, J. (2004). The concept of validity. Psychological Review, 111(4), 1061-1071.

https://doi.org/10.1037/0033-295X.111.4.1061

Brochu, P. M., Gawronski, B., \& Esses, V. M. (2011). The integrative prejudice framework and different forms of weight prejudice: An analysis and expansion. Group Processes \& Intergroup Relations, 14(3), 429-444. https://doi.org/10.1177/1368430210396520

Cameron, C. D., Brown-lannuzzi, J. L., \& Payne, B. K. (2012). Sequential priming measures of implicit social cognition: A meta-analysis of associations with behavior and explicit attitudes. Personality and Social Psychology Review, 16(4), 330-350.

https://doi.org/10.1177/1088868312440047

Chaiken, S., \& Trope, Y. (1999). Dual-process theories in social psychology (Vol. xiii). New York, NY: Guilford Press.

Conrey, F. R., Sherman, J. W., Gawronski, B., Hugenberg, K., \& Groom, C. J. (2005). Separating multiple processes in implicit social cognition: The quad model of implicit task performance. Journal of Personality and Social Psychology, 89(4), 469-487. https://doi.org/10.1037/00223514.89.4.469

Crosby, F., Bromley, S., \& Saxe, L. (1980). Recent unobtrusive studies of Black and White discrimination and prejudice: A literature review. Psychological Bulletin, 87(3), 546-563. https://doi.org/10.1037/00332909.87.3.546

De Houwer, J. (2003a). A structural analysis of indirect measures of attitudes. In J. Musch \& K. C. Klauer (Eds.), The psychology of evaluation: Affective processes in cognition and emotion (pp. 219-244). Mahwah, NJ, US: Lawrence Erlbaum Associates Publishers.

De Houwer, J. (2003b). The extrinsic affective Simon task. Experimental Psychology, 50(2), 77-85.

De Houwer, J. (2006). What Are Implicit Measures and Why Are We Using Them? In Handbook of implicit cognition and addiction (pp. 11-28).

Thousand Oaks, CA, US: Sage Publications, Inc. https://doi.org/10.4135/9781412976237.n2

De Houwer, J. (2009). Comparing measures of attitudes at the functional and procedural level: Analysis and implications. In R. H. Petty, R. H. Fazio, 
\& P. Brinol, Attitudes: Insights from the new implicit measures (pp. 361390). New York, NY: Psychology Press. Retrieved from http://users.ugent.be/ jdhouwer/bookpetty.pdf

De Houwer, J., \& De Bruycker, E. (2007). The implicit association test outperforms the extrinsic affective Simon task as an implicit measure of inter-individual differences in attitudes. British Journal of Social Psychology, 46(2), 401-421. https://doi.org/10.1348/014466606X130346

De Houwer, J., Geldof, T., \& De Bruycker, E. (2005). The implicit association test as a general measure of similarity. Canadian Journal of Experimental Psychology, 59(4), 228-239.

De Houwer, J., Heider, N., Spruyt, A., Roets, A., \& Hughes, S. (2015). The relational responding task: toward a new implicit measure of beliefs. Frontiers in Psychology, 6. https://doi.org/10.3389/fpsyg.2015.00319 De Houwer, J., \& Moors, A. (2010). Implicit measures: Similarities and differences. Handbook of Implicit Social Cognition: Measurement, Theory, and Applications, 176-193.

De Houwer, J., \& Moors, A. (2012). How to define and examine implicit processes. In Psychology of Science: Implicit and Explicit Processes (pp. 183-198). Oxford: Oxford University Press.

De Houwer, J., Teige-Mocigemba, S., Spruyt, A., \& Moors, A. (2009). Implicit measures: A normative analysis and review. Psychological Bulletin, 135(3), 347-368. https://doi.org/10.1037/a0014211

Devine, P. G. (1989). Stereotypes and prejudice: Their automatic and controlled components. Journal of Personality and Social Psychology, 56(1), 5-18.

Devine, P. G., Plant, E. A., Amodio, D. M., Harmon-Jones, E., \& Vance, S. L. (2002). The regulation of explicit and implicit race bias: the role of motivations to respond without prejudice. Journal of Personality and Social Psychology, 82(5), 835-848.

Doob, L. W. (1947). The behavior of attitudes. Psychological Review, 54(3), 135-156. https://doi.org/http://0-

dx.doi.org.pugwash.lib.warwick.ac.uk/10.1037/h0058371

Dunton, B. C., \& Fazio, R. H. (1997). An Individual Difference Measure of Motivation to Control Prejudiced Reactions. Personality and Social Psychology Bulletin, 23(3), 316-326.

https://doi.org/10.1177/0146167297233009

Fazio, R. H., \& Olson, M. A. (2014). The MODE model: Attitude-behavior process as a function of motivation and opportunities. In J. W. Sherman, 
B. Gawronski, \& Y. Trope, Dual-Process Theories of the Social Mind. New York, NY: Guilford Publications.

Fazio, R. H. (1990). Multiple processes by which attitudes guide behavior: The mode model as an integrative framework. Advances in Experimental Social Psychology, 23, 75-109. https://doi.org/10.1016/S00652601(08)60318-4

Fazio, R. H. (2007). Attitudes as object-evaluation associations of varying strength. Social Cognition, 25(5), 603-637. https://doi.org/10.1521/soco.2007.25.5.603

Fazio, R. H., Jackson, J. R., Dunton, B. C., \& Williams, C. J. (1995).

Variability in automatic activation as an unobtrusive measure of racial attitudes: A bona fide pipeline? Journal of Personality and Social Psychology, 69(6), 1013-1027. https://doi.org/http://dx.doi.org/10.1037/0022-3514.69.6.1013

Fazio, Russell H., \& Olson, M. A. (2003). Implicit measures in social cognition. research: their meaning and use. Annual Review of Psychology, 54, 297-327. https://doi.org/10.1146/annurev.psych.54.101601.145225

Fiedler, K., Messner, C., \& Bluemke, M. (2006). Unresolved problems with the ' $I$ ', the ' $A$ ', and the ' $T$ ': A logical and psychometric critique of the Implicit Association Test (IAT). European Review of Social Psychology, 17(1), 74-147. https://doi.org/10.1080/10463280600681248

Freud, S. (1915). The unconscious. Standard Edition, 14(1957), 159-215.

Freud, S. (2005). The Unconscious. London: Penguin Classics.

Friese, M., \& Fiedler, K. (2009). Being on the Lookout for Validity.

Experimental Psychology, 57(3), 228-232. https://doi.org/10.1027/16183169/a000051

Friese, M., Hofmann, W., \& Schmitt, M. (2009). When and why do implicit measures predict behaviour? Empirical evidence for the moderating role of opportunity, motivation, and process reliance. European Review of Social Psychology, 19(1), 285-338.

https://doi.org/10.1080/10463280802556958

Friese, M., Hofmann, W., \& Wänke, M. (2008). When impulses take over: moderated predictive validity of explicit and implicit attitude measures in predicting food choice and consumption behaviour. The British Journal of Social Psychology, 47, 397-419.

https://doi.org/10.1348/014466607X241540

Friese, M., Smith, C. T., Koever, M., \& Bluemke, M. (2016). Implicit measures of attitudes and political voting behavior: Implicit measures 
and political voting behavior. Social and Personality Psychology Compass, 10(4), 188-201. https://doi.org/10.1111/spc3.12246

Friese, M., Wänke, M., \& Plessner, H. (2006). Implicit consumer preferences and their influence on product choice. Psychology and Marketing, 23(9), 727-740. https://doi.org/10.1002/mar.20126

Gaertner, S., \& Bickman, L. (1971). Effects of race on the elicitation of helping behavior: The wrong number technique. Journal of Personality and Social Psychology, 20(2), 218-222.

https://doi.org/10.1037/h0031681

Galdi, S., Gawronski, B., Arcuri, L., \& Friese, M. (2012). Selective exposure in decided and undecided individuals: Differential relations to automatic associations and conscious beliefs. Personality and Social Psychology Bulletin, 38(5), 559-569. https://doi.org/10.1177/0146167211435981

Gawronski, B. (2009). Ten frequently asked questions about implicit measures and their frequently supposed, but not entirely correct answers. Canadian Psychology, 50(3), 141-150.

https://doi.org/10.1037/a0013848

Gawronski, B., \& Bodenhausen, G. V. (2006). Associative and propositional processes in evaluation: An integrative review of implicit and explicit attitude change. Psychological Bulletin, 132(5), 692-731. https://doi.org/10.1037/0033-2909.132.5.692

Gawronski, B., \& Bodenhausen, G. V. (2011). The associativepropositional evaluation model. In Advances in Experimental Social Psychology (Vol. 44, pp. 59-127). Elsevier. https://doi.org/10.1016/B9780-12-385522-0.00002-0

Gawronski, B., \& De Houwer, J. (2014). Implicit measures in social and personality psychology. In H. T. Reis \& C. M. Judd, Handbook of research methods in social and personality psychology (Vol. 2, pp. 283-310). New York, NY: Cambridge University Press.

Gawronski, B., Hofmann, W., \& Wilbur, C. J. (2006). Are 'implicit' attitudes unconscious? Consciousness and Cognition, 15(3), 485-499. https://doi.org/10.1016/j.concog.2005.11.007

Gawronski, B., \& LeBel, E. P. (2008). Understanding patterns of attitude change: When implicit measures show change, but explicit measures do not. Journal of Experimental Social Psychology, 44(5), 1355-1361. https://doi.org/10.1016/j.jesp.2008.04.005

Gawronski, B., Peters, K. R., Brochu, P. M., \& Strack, F. (2008). Understanding the relations between different forms of racial prejudice: 
a cognitive consistency perspective. Personality \& Social Psychology Bulletin, 34(5), 648-665. https://doi.org/10.1177/0146167207313729

Greenwald, A. G. (1990). What cognitive representations underlie social attitudes? Bulletin of the Psychonomic Society, 28(3), 254-260.

Greenwald, A. G., \& Banaji, M. R. (1995). Implicit social cognition: attitudes, self-esteem, and stereotypes. Psychological Review, 102(1), 427.

Greenwald, A. G., Banaji, M. R., \& Nosek, B. A. (2015). Statistically small effects of the Implicit Association Test can have societally large effects. Journal of Personality and Social Psychology, 108(4), 553-561. https://doi.org/10.1037/pspa0000016

Greenwald, A. G., Banaji, M. R., Rudman, L. A., Farnham, S. D., Nosek, B. A., \& Mellott, D. S. (2002). A unified theory of implicit attitudes, stereotypes, self-esteem, and self-concept. Psychological Review, 109(1), 3-25. https://doi.org/10.1037//0033-295X.109.1.3

Greenwald, A. G., McGhee, D. E., \& Schwartz, J. L. (1998). Measuring individual differences in implicit cognition: the implicit association test. Journal of Personality and Social Psychology, 74(6), 1464-1480.

Greenwald, A. G., \& Nosek, B. A. (2001). Health of the Implicit Association Test at age 3. Zeitschrift Für Experimentelle Psychologie, 48(2), 85-93.

Greenwald, A. G., \& Nosek, B. A. (2008). Attitudinal dissociation: What does it mean. Attitudes: Insights from the New Implicit Measures, 6582. Retrieved from http://citeseerx.ist.psu.edu/viewdoc/download?doi=10.1.1.158.8361\&re $p=r e p 1 \&$ type $=p d f$

Greenwald, A. G., Nosek, B. A., \& Banaji, M. R. (2003). Understanding and using the Implicit Association Test: I. An improved scoring algorithm. Journal of Personality and Social Psychology, 85(2), 197-216. https://doi.org/10.1037/0022-3514.85.2.197

Greenwald, A. G., Poehlman, T. A., Uhlmann, E. L., \& Banaji, M. R. (2009). Understanding and using the Implicit Association Test: III. Meta-analysis of predictive validity. Journal of Personality and Social Psychology, 97(1), 17-41. https://doi.org/10.1037/a0015575

Greenwald, A. G., \& Sriram, N. (2010). No measure Is perfect, but some measures can be quite useful. Experimental Psychology, 57(3), 238-242. https://doi.org/10.1027/1618-3169/a000075

Gregg, A. P., Seibt, B., \& Banaji, M. R. (2006). Easier done than undone: Asymmetry in the malleability of implicit preferences. Journal of 
Personality and Social Psychology, 90(1), 1-20.

https://doi.org/10.1037/0022-3514.90.1.1

Hahn, A., \& Gawronski, B. (2014). Do implicit evaluations reflect unconscious attitudes? Behavioral and Brain Sciences, 37(1), 28-29. https://doi.org/10.1017/S0140525X13000721

Hahn, A., \& Gawronski, B. (2015). Implicit social cognition. In J. D. Wright (Ed.), International Encyclopedia of the Social \& Behavioral Sciences (2nd ed.) (pp. 714-720). Oxford, UK: Elsevier. Retrieved from http://www.bertramgawronski.com/documents/HG_StevensHandbook.p df

Hahn, A., Judd, C. M., Hirsh, H. K., \& Blair, I. V. (2014). Awareness of implicit attitudes. Journal of Experimental Psychology. General, 143(3), 1369-1392. https://doi.org/10.1037/a0035028

Hofmann, W., Gawronski, B., Gschwendner, T., Le, H., \& Schmitt, M. (2005). A meta-analysis on the correlation between the Implicit Association Test and explicit self-report measures. Personality and Social Psychology Bulletin, 31(10), 1369-1385. https://doi.org/10.1177/0146167205275613

Hofmann, W., Gschwendner, T., Nosek, B. A., \& Schmitt, M. (2005). What moderates implicit-explicit consistency? European Review of Social Psychology, 16(1), 335-390. https://doi.org/10.1080/10463280500443228

Hofmann, W., Rauch, W., \& Gawronski, B. (2007). And deplete us not into temptation: Automatic attitudes, dietary restraint, and self-regulatory resources as determinants of eating behavior. Journal of Experimental Social Psychology, 43(3), 497-504. https://doi.org/10.1016/j.jesp.2006.05.004

Holtgraves, T. (2004). Social desirability and self-reports: testing models of socially desirable responding. Personality \& Social Psychology Bulletin, 30(2), 161-172. https://doi.org/10.1177/0146167203259930

Houben, K., \& Wiers, R. W. (2006). A test of the salience asymmetry interpretation of the alcohol-IAT. Experimental Psychology, 53(4), 292300. https://doi.org/10.1027/1618-3169.53.4.292

Jacoby, L. L., Toth, J. P., Lindsay, D. S., \& Debner, J. A. (1992). Lectures for a layperson: Methods for revealing unconscious processes. In R. F. Bornstein \& B. Pittman (Eds.), Perception without awareness: Cognitive, clinical, and social perspectives. New York, NY: Guilford Press. 
Jones, E. E., \& Sigall, H. (1971). The bogus pipeline: A new paradigm for measuring affect and attitude. Psychological Bulletin, 76(5), 349-364. https://doi.org/10.1037/h0031617

Jordan, C. H., Spencer, S. J., Zanna, M. P., Hoshino-Browne, E., \& Correll, J. (2003). Secure and defensive high self-esteem. Journal of Personality and Social Psychology, 85(5), 969-978. https://doi.org/10.1037/00223514.85.5.969

Karpinski, A. (2004). Measuring self-esteem using the Implicit Association Test: The role of the other. Personality and Social Psychology Bulletin, $30(1), 22-34$.

Karpinski, A., \& Steinman, R. B. (2006). The Single Category Implicit Association Test as a measure of implicit social cognition. Journal of Personality and Social Psychology, 91(1), 16-32.

https://doi.org/10.1037/0022-3514.91.1.16

Klauer, K. C., Voss, A., Schmitz, F., \& Teige-Mocigemba, S. (2007). Process components of the Implicit Association Test: A diffusion-model analysis. Journal of Personality and Social Psychology, 93(3), 353-368. https://doi.org/10.1037/0022-3514.93.3.353

Kunstman, J. W., \& Plant, E. A. (2008). Racing to help: racial bias in high emergency helping situations. Journal of Personality and Social Psychology, 95(6), 1499-1510. https://doi.org/10.1037/a0012822

Lai, C. K., Marini, M., Lehr, S. A., Cerruti, C., Shin, J.-E. L., Joy-Gaba, J. A., ... Nosek, B. A. (2014). Reducing implicit racial preferences: I. A comparative investigation of 17 interventions. Journal of Experimental Psychology. General, 143(4), 1765-1785. https://doi.org/10.1037/a0036260

LaPiere, R. T. (1934). Attitudes vs actions. Social Forces, 39(1), 230-237.

McFarland, S. G., \& Crouch, Z. (2002). A cognitive skill confound on the Implicit Association Test. Social Cognition, 20(6), 483-510.

Miller, G. A. (2003). The cognitive revolution: a historical perspective. Trends in Cognitive Sciences, 7(3), 141-144. https://doi.org/10.1016/S1364-6613(03)00029-9

Monteith, M. J., Voils, C. I., \& Ashburn-Nardo, L. (2001). Taking a look underground: Detecting, interpreting, and reacting to implicit racial biases. Social Cognition, 19(4), 395-417. https://doi.org/10.1521/soco.19.4.395.20759

Nisbett, R. E., \& Wilson, T. D. (1977). Telling more than we can know: Verbal reports on mental processes. Psychological Review, 84(3), 231. 
Nock, M. K., \& Banaji, M. R. (2007). Prediction of Suicide Ideation and Attempts Among Adolescents Using a Brief Performance-Based Test. Journal of Consulting and Clinical Psychology, 75(5), 707-715. https://doi.org/10.1037/0022-006X.75.5.707

Nock, M. K., Park, J. M., Finn, C. T., Deliberto, T. L., Dour, H. J., \& Banaji, M. R. (2010). Measuring the suicidal mind: Implicit cognition predicts suicidal behavior. Psychological Science, 21(4), 511-517. https://doi.org/10.1177/0956797610364762

Nosek, B. A. (2007). Implicit-Explicit Relations. Current Directions in Psychological Science, 16(2), 65-69. https://doi.org/10.1111/j.14678721.2007.00477.x

Nosek, B. A., Banaji, M., \& Greenwald, A. G. (2002). Harvesting implicit group attitudes and beliefs from a demonstration web site. Group Dynamics: Theory, Research, and Practice, 6(1), 101-115. https://doi.org/10.1037/1089-2699.6.1.101

Nosek, B. A., \& Banaji, M. R. (2001). The Go/No-Go Association Task. Social Cognition, 19(6), 625-666. https://doi.org/10.1521/soco.19.6.625.20886

Nosek, B. A., Greenwald, A. G., \& Banaji, M. R. (2005). Understanding and using the Implicit Association Test: II. Method variables and construct validity. Personality and Social Psychology Bulletin, 31(2), 166-180. https://doi.org/10.1177/0146167204271418

Nosek, B. A., Greenwald, A. G., \& Banaji, M. R. (2007). The Implicit Association Test at age 7: A methodological and conceptual review. Automatic Processes in Social Thinking and Behavior, 265-292.

Nosek, B. A., \& Hansen, J. J. (2008a). Personalizing the Implicit Association Test increases explicit evaluation of target concepts. European Journal of Psychological Assessment, 24(4), 226-236.

Nosek, B. A., \& Hansen, J. J. (2008b). The associations in our heads belong to us: Searching for attitudes and knowledge in implicit evaluation. Cognition \& Emotion, 22(4), 553-594. https://doi.org/10.1080/02699930701438186

Nosek, B. A., Hawkins, C. B., \& Frazier, R. S. (2011). Implicit social cognition: From measures to mechanisms. Trends in Cognitive Sciences, 15(4), 152-159. https://doi.org/10.1016/j.tics.2011.01.005

Nosek, B. A., \& Smyth, F. L. (2007). A multitrait-multimethod validation of the Implicit Association Test: implicit and explicit attitudes are related but distinct constructs. Experimental Psychology, 54(1), 14-29. https://doi.org/10.1027/1618-3169.54.1.14 
Nosek, B. A., Smyth, F. L., Hansen, J. J., Devos, T., Lindner, N. M., Ranganath, K. A., ... Banaji, M. R. (2007). Pervasiveness and correlates of implicit attitudes and stereotypes. European Review of Social Psychology, 18(1), 36-88. https://doi.org/10.1080/10463280701489053

Nosek, B. A., Smyth, F. L., Sriram, N., Lindner, N. M., Devos, T., Ayala, A., ... Greenwald, A. G. (2009). National differences in gender-science stereotypes predict national sex differences in science and math achievement. Proceedings of the National Academy of Sciences, 106(26), 10593-10597. https://doi.org/10.1073/pnas.0809921106

Olson, M. A., \& Fazio, R. H. (2001). Implicit attitude formation through classical conditioning. Psychological Science, 12(5), 413-417. https://doi.org/10.1111/1467-9280.00376

Olson, M. A., Fazio, R. H., \& Han, H. A. (2009). Conceptualizing personal and extrapersonal associations. Social and Personality Psychology Compass, 3(2), 152-170.

O'Shea, B., Watson, D. G., \& Brown, G. D. A. (2016). Measuring implicit attitudes: A positive framing bias flaw in the Implicit Relational Assessment Procedure (IRAP). Psychological Assessment, 28(2), 158-170. https://doi.org/10.1037/pas0000172

Oskamp, S., \& Schultz, P. W. (2005). Attitudes and Opinions (3rd ed.). Mahwah, NJ: Lawrence Erlbaum Associates.

Oswald, F. L., Mitchell, G., Blanton, H., Jaccard, J., \& Tetlock, P. E. (2013). Predicting ethnic and racial discrimination: a meta-analysis of IAT criterion studies. Journal of Personality and Social Psychology, 105(2), 171-192. https://doi.org/10.1037/a0032734

Payne, B. K., Burkley, M. A., \& Stokes, M. B. (2008). Why do implicit and explicit attitude tests diverge? The role of structural fit. Journal of Personality and Social Psychology, 94(1), 16-31. https://doi.org/10.1037/0022-3514.94.1.16

Payne, B. K., \& Gawronski, B. (2010). A history of implicit social cognition: Where is it coming from? Where is it now? Where is it going. In $B$. Gawronski \& K. B. Payne, Handbook of implicit social cognition: Measurement, theory, and applications (pp. 1-15). New York, NY: Guilford Press.

Perugini, M., Richetin, J., \& Zogmaister, C. (2010). Prediction of behavior. In B. Gawronski \& B. K. Payne (Eds.), Handbook of implicit social cognition: Measurement, theory, and applications (pp. 255-277). New York, NY, US: Guilford Press. 
Peters, K. R., \& Gawronski, B. (2011). Mutual influences between the implicit and explicit self-concepts: The role of memory activation and motivated reasoning. Journal of Experimental Social Psychology, 47(2), 436-442. https://doi.org/10.1016/j.jesp.2010.11.015

Ranganath, K. A., Smith, C. T., \& Nosek, B. A. (2008). Distinguishing automatic and controlled components of attitudes from direct and indirect measurement methods. Journal of Experimental Social Psychology, 44(2), 386-396. https://doi.org/10.1016/j.jesp.2006.12.008

Richetin, J., Perugini, M., Adjali, I., \& Hurling, R. (2007). The moderator role of intuitive versus deliberative decision making for the predictive validity of implicit and explicit measures. European Journal of Personality, 21(4), 529-546. https://doi.org/10.1002/per.625

Roddy, S., Stewart, I., \& Barnes-Holmes, D. (2010). Anti-fat, pro-slim, or both? Using two reaction-time based measures to assess implicit attitudes to the slim and overweight. Journal of Health Psychology, 15(3), 416-425. https://doi.org/10.1177/1359105309350232

Roddy, S., Stewart, I., \& Barnes-Holmes, D. (2011). Facial reactions reveal that slim is good but fat is not bad: Implicit and explicit measures of body-size bias. European Journal of Social Psychology, 41(6), 688-694. https://doi.org/10.1002/ejsp.839

Rooth, D. O. (2010). Automatic associations and discrimination in hiring: Real world evidence. Labour Economics, 17(3), 523-534. https://doi.org/10.1016/j.labeco.2009.04.005

Rothermund, K., \& Wentura, D. (2001). Figure-ground asymmetries in the Implicit Association Test (IAT). Zeitschrift Fur Experimentelle Psychologie, 48(2), 94-106.

Rothermund, K., \& Wentura, D. (2010). It's brief but is it better? An evaluation of the brief implicit association test. Experimental Psychology, 57(3), 233-237. https://doi.org/10.1027/1618-3169/a000060

Rothermund, K., Teige-Mocigemba, S., Gast, A., \& Wentura, D. (2009). Minimizing the influence of recoding in the Implicit Association Test: the Recoding-Free Implicit Association Test (IAT-RF). Quarterly Journal of Experimental Psychology, 62(1), 84-98. https://doi.org/10.1080/17470210701822975

Rothermund, K., \& Wentura, D. (2004). Underlyinp Processes in the implicit association test: Dissociating salience from associations. Journal of Experimental Psychology: General, 133(2), 139-165.

https://doi.org/10.1037/0096-3445.133.2.139 
Rothermund, K., Wentura, D., \& De Houwer, J. (2005). Validity of the salience asymmetry account of the Implicit Association Test: Reply to Greenwald, Nosek, Banaji, and Klauer (2005). Journal of Experimental Psychology: General, 134(3), 426-430. https://doi.org/10.1037/00963445.134.3.426

Schacter, D. L., Chiu, C.-Y. P., \& Ochsner, K. N. (1993). Implicit memory: A selective review. Annual Review of Neuroscience, 16(1), 159-182.

Sheeran, P. (2002). Intention-Behavior Relations: A Conceptual and Empirical Review. European Review of Social Psychology, 12(1), 1-36. https://doi.org/10.1080/14792772143000003

Shiffrin, R. M., \& Schneider, W. (1977). Controlled and automatic human information processing: II. Perceptual learning, automatic attending and a general theory. Psychological Review, 84(2), 127-190.

https://doi.org/10.1037/0033-295X.84.2.127

Smith, C. T., \& Nosek, B. A. (2011). Affective focus increases the concordance between implicit and explicit attitudes. Social Psychology, 42(4), 300-313. https://doi.org/10.1027/1864-9335/a000072

Spence, A., \& Townsend, E. (2008). Spontaneous evaluations: Similarities and differences between the affect heuristic and implicit attitudes.

Cognition and Emotion, 22(1), 83-93.

https://doi.org/10.1080/02699930701298432

Strack, F., \& Deutsch, R. (2004). Reflective and impulsive determinants of social behavior. Personality and Social Psychology Review, 8(3), 220-247.

Teige-Mocigemba, S., Klauer, K. C., \& Sherman, J. W. (2010). A practical guide to the Implicit Association Test and related tasks. In B. Gawronski \& B. K. Payne, Handbook of implicit social cognition: Measurement, theory and applications. New York, NY: Guilford Press.

Teige-Mocigemba, Sarah, Klauer, K. C., \& Rothermund, K. (2008). Minimizing method-specific variance in the IAT. European Journal of Psychological Assessment, 24(4), 237-245. https://doi.org/10.1027/10155759.24.4.237

Wentura, D., \& Rothermund, K. (2007). Paradigms we live by. A plea for more basic research on the IAT. In B. Wittenbrink \& N. Schwarz, Implicit measures of attitudes (pp. 195-215). New York: Guilford Press. 


\section{To cite this article:}

O'Shea, B. (2018). Can implicit measures contribute to a true understanding of people's attitudes and stereotypes? Exchanges: The Interdisciplinary Research Journal, 5(2), 106-131. Retrieved from: http://exchanges.warwick.ac.uk/index.php/exchanges/article/view/233

\footnotetext{
' For a more recent review of the relationship between attitudes (intentions) and behaviour see Sheeran (2002).

ii For a review of unobtrusive methods see Crosby, Bromley, \& Saxe, 1980 and for a recent example of the unobtrusive technique showing that white people offer less help to black individuals relative to white individuals in an emergency situation, see Kunstman \& Plant, 2008.

iii For a review see Schacter, Chiu, \& Ochsner, 1993.

iv For a review see Blair, 2002.

${ }^{\vee}$ O'Shea et al. (2016) also introduced a new implicit measure called the Simple Implicit Procedure (SIP) to overcome the limitations in the IRAP.

vi See Fazio and Olson (2003), Gawronski (2009), Gawronski and De Houwer (2014), and Nosek et al. (2011), for reviews and lists of other implicit measures that have received less attention.

vii For a review see Hofmann, Gschwendner, Nosek, \& Schmitt, 2005.

viii For review of this topic, see Friese, et al., 2009.
} 